\title{
Reseña de HEIDEGGER, Martin. (2019). De la experiencia del pensar. (Traducción y prólogo de Alberto Constante y Ricardo Horneffer). México: Pitzilein Books.
}

\author{
Román Leyva Hernández
}

En el primer cuarteto de un conocido soneto, Quevedo dice lo siguiente: "Retirado en la paz de estos desiertos/con pocos, pero doctos libros juntos / vivo en conversación con los difuntos / y escucho con mis ojos a los muertos". Además de bellamente dicha, la idea es clara: mediante la lectura se establece un diálogo con los que ya no están, pero que nos conforman, porque aún podemos escucharlos. Sin embargo, para que el diálogo se dé efectivamente, no basta sólo con la escucha, porque el texto también debe decirnos algo, debe hablarnos. Y cuando se trata de un texto que no está en la lengua materna, la traducción juega un papel determinante, pues mediante ella puede o no hablarnos y, en consecuencia, ofrecer la posibilidad de entablar un diálogo. Esto significa, entre otras cosas, que traducir es interpretar, como bien lo señala Heidegger a lo largo de su obra, así como en De la experiencia del pensar: "Lo hablado nunca es, en lengua alguna, lo dicho." (Heidegger, 2019: 57). Esta diferencia crucial entre Rede [lo hablado] y Sprache [lo dicho] la conocen bien Alberto Constante y Ricardo Horneffer, que en este caso ofrecen una nueva traducción de Aus der Erfahurng des Denkens ${ }^{1}$ junto con un prólogo, en una edición bilingüe (alemán/español) realizada por la editorial Pitzilein Books, México, 2019.

Escrito en forma aforística en 1947 e incluido en el volumen 13 de la Gesamtausgabe, De la experiencia del pensar ya no es el "típico ensayo filosófico" al que

\footnotetext{
${ }^{1}$ Menciono algunas otras traducciones que se han realizado de este texto. R. Barce, "De la experiencia del pensar" en, Palos de la crítica, 41/2 (abril-septiembre 1981); F. Duque, "Desde la experiencia del pensar". Madrid: Abada, 2005; J. B. Llinares, "Desde la experiencia del pensamiento", texto trilingüe. Barcelona: península, 1986; A. García Astrada, "La experiencia del pensar" seguido de Hebel, el amigo de la casa. Córdoba: Ediciones del copista, 2007.
} 
Heidegger recurría en sus primeros trabajos, divididos en parágrafos y estructura capitular. Más bien, el autor opta por abrir otro camino para reconsiderar y replantear una serie de temáticas que son recurrentes en sus textos: el ser, el lenguaje, el pensar y la experiencia.

Esto último, de alguna manera, viene a cuestionar la creencia general de que el pensamiento de Martin Heidegger está enfocado a un único tema: el ser. La cuestionabilidad es viable sobre todo teniendo en cuenta que la obra de este pensador alemán parece dar indicios de lo contrario, o, ¿̇acaso es factible englobar de manera general en el "ser" (Sein) formulaciones como Seyn, Lichtung, Geviert, Ereignis o die Sache (des Denkens)? Esta pregunta emana de la sugerente traducción de Alberto Constante y Ricardo Horneffer del arcaico Seyn alemán por seer, antigua forma espańola del verbo "ser", que los traductores hallaron en el Cantar del Mio Cid. ¿Refiere a lo mismo ser que seer?

Aunado a lo anterior, también habría que recordar que ya desde Ser y tiempo, y quizá desde un poco antes, Heidegger enfatizaba, echando mano de los indicadores formarles (Formale Anzeigen), que los existenciarios, en contraste con los conceptos (Begriffe) y categorías, carecían de contenido, puesto que no señalaban algo quiditativo de aquello a lo que apuntaban. De esto se desprende una pregunta no poco importante, ¿por qué Heidegger se opone, al parecer, a conceptualizar? La lectura de algunos de los aforismos de De la experiencia del pensar, referidos al término de experiencia, podría ayudar a responder estas interrogantes.

Por experiencia se entiende, predominantemente, una especie de acumulación de ciertos casos particulares, semejantes entre sí, que pueden dar paso a una regla general que, posteriormente, nos permita actuar en otros futuros casos parecidos. De aquí que se diga que alguien es experto, perito en algo, o que sea un hombre de mucha experiencia. Como se puede apreciar, esta idea predominante de ex/periencia hace mayor énfasis en la pericia, que en el prefijo $e x .^{2}$ Con base en esta idea de experiencia, podría decirse que Heidegger es un experto en el tema del ser.

Sin embargo, frente a esta idea de experiencia, Heidegger mismo ofrece otra que, si bien no es totalmente contraria a la anteriormente expuesta, sí es diferente. Dicho de otra manera, el autor de Aus der Erfahurng des Denkens pone mayor énfasis no tanto en la pericia, sino en el prefijo ex, el cual significa "salir", "estar fuera". Es decir, "estar fuera de pericia", "salir de la pericia". En este sentido, habría que decir que, propiamente dicho, el pensador es im-perito en toda materia, en cualquier

\footnotetext{
${ }^{2}$ Según Joan Corominas, experiencia proviene del latín "experientia". Palabra derivada del participio "perito", que justo significa lo que en espańol actual, "experto en algo" "entendido en algo". Cfr., Corominas (1987).
} 
tema, pues, en sentido estricto, aquello a lo que se vuelca la tarea del pensador no es un objeto de investigación. Por esto anota Heidegger: "Pocos son los suficientemente experimentados en distinguir entre un objeto aprendido [gelehrten Gegenstand] y una cosa pensada [gedachten Sache]" (Heidegger, 2019:33).

Recorrer sistemáticamente un mismo camino es viable sólo para el experto, pues tiene un objeto determinado de investigación. Pero para el pensador, la sistematicidad de recorrer el mismo camino no es viable, porque aquello por lo que interroga no es algo delimitado, definido. Por esto, al pensador le corresponde, desde la perspectiva heideggeriana, estar en camino constantemente. O como anota Heidegger en otro aforismo: "Ponerse en camino a una estrella, sólo esto" (Heidegger, 2019:29). Bajo esta otra idea de experiencia, habría que decir que Seyn, Lichtung, Geviert, Ereignis o die Sache (des Denkens), más que conceptos que refieren al ser (Sein), son caminos abiertos que intentan nombrar lo pensado por ellos.

En este sentido, De la experiencia del pensar es otro camino recorrido y, por lo tanto, otra experiencia, en la que Heidegger se acerca al pensar, al ser y al lenguaje. Un camino donde los aforismos sustituyen al concepto y a la categoría; donde el pensar (Denken) se acerca más al recuerdo (Andenken) y al poetizar (Dichten), que a la representación y al cálculo; donde se intenta ir más allá de la filosofía, dando un paso atrás (Schritt zurück), para pensar lo no pensado por ella.

De lo que se trata, en fin, es no dar toda respuesta y formulación por definitiva y definitoria, de lo que se trata es prestar la mayor atención a aquello por lo que se interroga y dejar que lo interrogado tome la palabra. Como anota Heidegger: "Tan pronto como tenemos la cosa [Sache] ante los ojos, y nuestro corazón presta oídos a la palabra, brota el pensar" (Heidegger, 2019:33). 


\section{Bibliografía}

Corominas, J. (1987). Breve diccionario etimológico de la lengua castellana. España: Gredos.

Heidegger, M. (2019) De la experiencia del pensar. (Traducción y prólogo de Alberto Constante y Ricardo Horneffer). México: Pitzilein Books. 